\title{
Prevalence and factors associated with dengue fever among febrile patients attending secondary health facilities in Kano metropolis, Nigeria
}

\author{
${ }^{*} 1,2$ Abdulaziz, M. M., ${ }^{2}$ Ibrahim, A., ${ }^{3}$ Ado, M., ${ }^{4}$ Ameh, C., ${ }^{4}$ Umeokonkwo, C., \\ ${ }^{5}$ Sufyan, M. B., ${ }^{4}$ Balogun, M. S., and ${ }^{6}$ Ahmed, S, A. \\ ${ }^{1}$ Nigeria Field Epidemiology and Laboratory Training Programme (NFELTP) \\ ${ }^{2}$ Department of Medical Microbiology, College of Medical Sciences, Ahmadu Bello University and Teaching \\ Hospital, Zaria, Kaduna State, Nigeria \\ ${ }^{3}$ Molecular Laboratory, Aminu Kano Teaching Hospital, Kano, Nigeria \\ ${ }^{4}$ Africa Field Epidemiology Network (AFENET) \\ ${ }^{5}$ Department of Community Medicine, College of Medical Sciences, Ahmadu Bello University and Teaching \\ Hospital, Zaria, Kaduna State, Nigeria \\ ${ }^{6}$ Department of Morbid Anatomy, College of Medical Sciences, Ahmadu Bello University and Teaching Hospital, \\ Zaria, Kaduna State, Nigeria \\ Correspondence to: mukaziz@yahoo.com
}

\begin{abstract}
:
Background: The Nigeria Centre for Disease Control (NCDC) has categorized dengue fever as a priority epidemic-prone disease. Kano metropolis is a hub for international trade and has seen rapid population growth with unplanned urbanisation. This provides the right environment for dengue virus transmission and spread. Most fevers in Nigeria and Kano in particular are treated as malaria or typhoid. This study aimed to determine the prevalence and factors associated with dengue fever and dengue-malaria co-infection among febrile patients in Kano metropolis.

Methodology: We conducted a hospital-based cross-sectional study among febrile patients attending secondary health facilities in Kano metropolis. We used multistage sampling technique to recruit 440 participants into the study. An interviewer administered structured questionnaire was used to collect participants' information, while blood was screened for malaria using rapid diagnostic test (RDT) kit and tested for dengue fever using an ELISA kit for dengue IgM. Data was cleaned and analysed using Microsoft Excel 2016 and Epi Info version 7.2 to calculate frequencies, proportions and odds ratios.

Results: The median age of participants was 24 years (IQR $=13-36$ years) while the age-group most represented was the 10-19 years' age group with $97(22.9 \%)$ participants. Males constituted $257(60.6 \%)$ while most were single $238(56.1 \%)$. Dengue IgM was positive for $332(78.3 \%)$, while malaria RDT was positive for $81(19.1 \%)$ and $67(15.8 \%)$ were positive for both. Those aged above 25 years were less likely to present with dengue fever $(\mathrm{OR}=0.6 ; 95 \% \mathrm{CI}=0.33-0.97)$. Dengue fever contributes a high percentage to febrile illnesses seen in Kano metropolis. Significant proportions of febrile patients have both dengue and malaria co-infection. None of the participants had dengue as a presumptive diagnosis.

Conclusion: These findings imply dengue fever should feature as a prominent differential for febrile illnesses and dengue screening tests should be made available for all cases seen in Kano.
\end{abstract}

Keywords: seroprevalence; dengue fever; RDT; secondary health facilities; Nigeria

Received January 17, 2020; Revised May 20, 2020; Accepted May 21, 2020

Copyright 2020 AJCEM Open Access. This article is licensed and distributed under the terms of the Creative Commons Attrition 4.0 International License <a rel="license" href="http://creativecommons.org/licenses/by/4.0/", which permits unrestricted use, distribution and reproduction in any medium, provided credit is given to the original author(s) and the source.

\section{Prévalence et facteurs associés à la dengue chez les patients fébriles fréquentant les établissements de santé secondaires de la métropole de Kano, au Nigéria}

\author{
*1,2Abdulaziz, M. M., ${ }^{2}$ Ibrahim, A., ${ }^{3}$ Ado, M., ${ }^{4}$ Ameh, C., ${ }^{4}$ Umeokonkwo, C., \\ ${ }^{5}$ Sufyan, M. B., ${ }^{4}$ Balogun, M. S., et ${ }^{6}$ Ahmed, S, A.
}

${ }^{1}$ Programme d'épidémiologie de terrain et de formation en laboratoire au Nigéria (NFELTP)

${ }^{2}$ Département de microbiologie médicale, Collège des sciences médicales, Université Ahmadu Bello et hôpital 
universitaire, Zaria, État de Kaduna, Nigéria

${ }^{3} \mathrm{M}$ Laboratoire moléculaire, Hôpital universitaire d'Aminu Kano, Kano, Nigéria

${ }^{4}$ Réseau d'épidémiologie de terrain en Afrique (AFENET)

${ }^{5}$ Département de médecine communautaire, Collège des sciences médicales, Université Ahmadu Bello et

hôpital universitaire, Zaria, État de Kaduna, Nigéria

${ }^{6}$ Département d'anatomie morbide, Collège des sciences médicales, Université Ahmadu Bello et hôpital universitaire, Zaria, État de Kaduna, Nigéria

Correspondance avec: mukaziz@yahoo.com

\begin{abstract}
Abstrait:
Contexte: Le Nigeria Center for Disease Control (NCDC) a classé la dengue parmi les maladies à tendance épidémique prioritaires. La métropole de Kano est une plaque tournante du commerce international et a connu une croissance démographique rapide avec une urbanisation imprévue. Cela fournit le bon environnement pour la transmission et la propagation du virus de la dengue. La plupart des fièvres au Nigeria et à Kano en particulier sont traitées comme le paludisme ou la typhoïde. Cette étude visait à déterminer la prévalence et les facteurs associés à la dengue et à la co-infection dengue-paludisme chez les patients fébriles de la métropole de Kano. Méthodologie: Nous avons mené une étude transversale en milieu hospitalier auprès de patients fébriles fréquentant des établissements de santé secondaires de la métropole de Kano. Nous avons utilisé une technique d'échantillonnage en plusieurs étapes pour recruter 440 participants dans l'étude. Un questionnaire structuré administré par un intervieweur a été utilisé pour collecter les informations des participants, tandis que le sang a été testé pour le paludisme à l'aide d'un kit de test de diagnostic rapide (TDR) et testé pour la dengue à l'aide d'un kit ELISA pour les IgM de la dengue. Les données ont été nettoyées et analysées à l'aide de Microsoft Excel 2016 et d'Epi Info version 7.2 pour calculer les fréquences, les proportions et les rapports de cotes. Résultats: L'âge médian des participants était de 24 ans (IQR=13-36 ans) tandis que le groupe d'âge le plus représenté était le groupe d'âge 10-19 ans avec 97 (22,9\%) participants. Les hommes en constituaient 257 $(60,6 \%)$ tandis que la plupart étaient célibataires $238(56,1 \%)$. Les IgM de la dengue étaient positives pour 332 $(78,3 \%)$, tandis que les TDR du paludisme étaient positifs pour $81(19,1 \%)$ et $67(15,8 \%)$ étaient positifs pour les deux. Les personnes âgées de plus de 25 ans étaient moins susceptibles de présenter une fièvre dengue $(\mathrm{OR}=0,6$; IC à $95 \%=0,33-0,97)$. La dengue contribue à un pourcentage élevé des maladies fébriles observées dans la métropole de Kano. Des proportions significatives de patients fébriles présentent une co-infection à la fois par la dengue et le paludisme. Aucun des participants n'avait de dengue comme diagnostic présumé.

Conclusion: Ces résultats impliquent que la dengue devrait apparaître comme un différentiel important pour les maladies fébriles et des tests de dépistage de la dengue devraient être disponibles pour tous les cas observés à Kano.
\end{abstract}

Mots-clés: séroprévalence; la fièvre de la dengue; RDT; établissements de santé secondaires; Nigeria

\section{Introduction:}

Dengue fever (DF), one of the Neglected Tropical Diseases (NTDs), accounts for about 96 million (95\% CI $67-136$ million) clinically apparent infections annually (1). It affects large populations especially in the tropics and subtropics (2). The World Health Organization (WHO) designated it "a disease that may constitute public health emergency of international concern with implication for health security" (3). Unfortunately, it is underrecognized and often misdiagnosed because of similarities in the presenting features with malaria and typhoid fever which are more easily diagnosed (4). Infected humans and monkeys are the reservoirs of the virus to uninfected Aedes mosquitoes. Treatment is by early supportive management since no antiviral agent is available. The first dengue vaccine, Dengvaxia, was registered in Mexico in December, 2015 (5).

The Aedes vector has wide distribution in Africa enabling extensive transmission of the virus (4), but records of dengue occurrence in Africa is poor (1). However, denguelike illnesses do occur but unfortunately are misdiagnosed (2). Documentation of dengue has come mostly from individual sero-surveys or from diagnosis in travellers returning from Africa and from outbreak investigations. Available data shows that dengue is endemic in 34 countries from all regions of Africa (4), and in the 50 years from 1960 to 2010, twenty laboratory-confirmed dengue outbreaks were reported in 15 countries, mostly from East Africa (4). Bhatt et al., in 2013 (1), using a formal modelling framework to map the global distribution of dengue risk, estimated there to be about 64.1 million dengue infections in Africa annually, of which 15.7 million manifests clinically.

Due to poor surveillance and lack of reporting in Nigeria (6), limited local prevalence studies have been the source of information on dengue magnitude (7-10). The Nigeria Centre for Disease Control (NCDC) has categorized dengue fever as a priority epidemicprone disease (11). Anecdotal data show increasing number of patients being managed in Kano for malaria with standard treatments ending with poor outcomes like death and loss of consciousness in adults. These cases could be DF or its severe form. Kano metropolis is a hub for international trade and has seen rapid population growth with unplanned urbani- 
zation. It has a lot of slums with open drainages, sewages, open empty containers (12), poor waste management (13)and plenty of ponds providing the right environment for Aedes. With no policy for routine detection, it is important to know whether some of the febrile cases with severe presentation are DF but missed because they are not looked for. We aimed to determine the proportion of patients presenting with fever who have DF and dengue-malaria co-infection at secondary health facilities in Kano metropolis and the proportion of missed diagnosis among febrile patients.

\section{Materials and method:}

\section{Study setting, design and population}

We conducted a hospital-based crosssectional study in November 2017 among febrile patients attending General Outpatient Departments (GOPD) of secondary health facilities in Kano metropolis. Kano metropolis is made of eight local government areas (LGA) with 12 secondary health facilities.

\section{Sample size and sampling technique}

We used a dengue-malaria co-infection prevalence of $43 \%$ (14) and assumed a non-response rate of $15 \%$ (considering the fact that blood samples will be taken and the possibility of decline or of lysed samples) and obtained a minimum sample size of 440 . We used multistage sampling technique to recruit patients into the study. In the first stage, two LGAs were selected out of the eight that make up Kano metropolis by balloting. In the second stage, we selected one hospital by balloting from the list of secondary health facilities located in each of the LGAs selected above; Waziri Shehu Gidado General Hospital (WS $\mathrm{GH}$ ) in Ungogo (with monthly average number of febrile patients of 1980) and Murtala Muhammad Specialist Hospital (MMSH) in Kano municipal (this hospital serves like a referral centre for the less privileged because a lot of services are free and has a particularly high monthly average turnover of febrile patients of 4200 ).

The sample size was allocated to the hospitals proportionate to the average monthly turnover of febrile patients, thus WSGH had 141 participants while MMSH had 299. In the third stage, we used a sampling interval of 14 to systematically recruit patients into the study in each of the participating hospitals until the proportion of the sample size allocated to the hospital was achieved. A total of 440 patients were recruited for the study.

\section{Inclusion and exclusion criteria}

We included patients with fever $\geq 38^{\circ} \mathrm{C}$ in the last two weeks prior enrolment, who were being tested for malaria or typhoid fever. Patients with jaundice, children under 6 months of age or patients with fever from other known causes such as upper or lower respiratory tract infections, urinary tract infections and bacterial sepsis were excluded.

\section{Data collection}

An interviewer administered, pre-tested, structured questionnaire was used to collect information on sociodemographic characteristics, signs and symptoms of the current illness, household and environmental factors.

\section{Sample collection}

Whole blood was collected from each subject, a portion of which was used to screen for malaria using rapid diagnostic test (RDT) kit (SD Bioline), and the other portion was then separated and serum stored at $-20^{\circ} \mathrm{C}$ until tested for DF IgM using an Enzyme Linked Immunosorbent Assay (ELISA) test kit (DeMeditec). This test is a qualitative immunoenzymatic determination of specific antibodies based on the ELISA technique. After the preparatory step involving dilution of the serum samples, the diluted samples were added to microplates which have been coated with specific antigens to bind corresponding antibodies in the sample.

After washing the wells to remove all unbound sample materials, a horseradish peroxidase (HRP) labelled conjugate was added, which binds to the captured antibodies. Following a second washing step, the unbound conjugate was removed. The immune complex formed by the bound conjugate was subsequently visualized by adding Tetramethylbenzidine (TMB) substrate which gives a blue reaction product. The intensity of this product was proportional to the amounts of specific antibodies in the sample. The reaction was stopped by adding sulphuric acid producing a yellow colour at endpoint. Absorbance was read at $450 \mathrm{~nm}$ using an ELISA microwell plate reader within $30 \mathrm{~min}$ of stopping the reaction. All absorbance readings were subjected to the test validation criteria as provided by the kit manufacturer, then converted to international units (U) before interpretation as positive, negative or indeterminate. All indeterminate results were categorized as negative as repeat sample collection was not possible.

\section{Statistical analysis}

Data collected were cleaned and analysed using Microsoft Excel 2016 and Epi Info 7.2. Univariate analyses were presented as frequencies and proportions in tables. Relationship between DF and sociodemographic (Iow educational status included those with no formal education, primary or secondary edu- 
cation), household, and environmental factors were examined and presented as odds ratios, with their 95\% confidence intervals and $p$ value. We used binary logistic regression model to determine independent predictors of DF.

\section{Ethical approval}

Ethical approval was obtained from the operational research committee of the Kano State Ministry of Health (KSMOH) with reference number MOH/Off/797/T.1/499. Written informed consent was sought from the participants, and where participants were less than 10 years old, consent was sought from their caregivers. For participants $10-14$ years of age, parental consent and individual assent were obtained. Failure to give consent or opting out of the study did not negatively affect client's management. Participants were notified of their malaria status to take back to their physicians for further management, while results of dengue status which became available much later were shared with the hospitals in which the study was conducted, and $\mathrm{KSMOH}$ to guide change in policy.

\section{Results:}

Of the 440 febrile patients recruited,
424 participated fully in all components of the study. Two hundred and fifty-seven (60.6\%) were male. The median age was 24 years (IQR =13-36) while the age-group most represented was the 10-19 years with 97 (22.9\%) subjects. More than half were single (55.4\%). Majority of the patients had attained secondary education 215 (50.7\%), while most were either unemployed $223(52.6 \%)$ or students $85(20.0 \%)$ (Table 1 ).

Dengue IgM was positive in 332 (78.3\%), malaria RDT was positive in 81 $(19.1 \%)$ while both were positive in 67 $(15.8 \%)$. Almost half of the cases, 197 $(46.5 \%)$, had malaria as the health providers' preliminary diagnosis (Table 2 ). The agegroup 20-29 years had the highest agespecific dengue IgM prevalence (Table 3). On bivariate analysis, those who were less than 25 years were twice more likely to have dengue infection $(\mathrm{OR}=2.1 ; 95 \% \mathrm{CI}=1.29$ 3.33). Having a house near bush $(O R=0.6$; $0.36-0.96)$, and having open water containers around the house $(\mathrm{OR}=0.5 ; 0.29-0.74)$ were also statistically significant but appeared protective (Table 4). Following unconditional logistic regression, none of these factors was an independent predictor of DF (Table 5).

Table 2: Status of dengue IgM among febrile patients and physicians' preliminary diagnosis in Kano metropolis, November, 2017

\begin{tabular}{lcc}
\hline Variable & Frequency $(\mathrm{n})$ & \\
\hline Test results $(\mathbf{n}=\mathbf{4 2 4})$ & 332 & 78.3 \\
Positive for Dengue IgM only & 81 & 19.1 \\
Positive for Malaria RDT only & 67 & 15.8 \\
Positive for both Dengue and Malaria & & \\
Health providers preliminary diagnosis & 197 & 46.5 \\
Malaria & 1 & 0.2 \\
Malaria and Typhoid & 88 & 20.8 \\
Typhoid & 138 & 32.6 \\
Not provided & & 100.0 \\
Proportion of missed diagnosis & & \\
\hline
\end{tabular}


Table 1: Sociodemographic characteristics of febrile patients in Kano metropolis, November 2017

\begin{tabular}{|c|c|c|}
\hline Characteristics & $\begin{array}{c}\text { Frequency } \\
(n=424)\end{array}$ & $\%$ \\
\hline \multicolumn{3}{|l|}{ Age group (years) } \\
\hline $10-19$ & 97 & 22.9 \\
\hline $20-29$ & 83 & 19.6 \\
\hline $30-39$ & 80 & 18.9 \\
\hline $40-49$ & 62 & 14.6 \\
\hline$\geq 50$ & 21 & 5.0 \\
\hline \multicolumn{3}{|l|}{ Gender } \\
\hline Female & 167 & 39.4 \\
\hline Male & 257 & 60.6 \\
\hline \multicolumn{3}{|l|}{ Marital status } \\
\hline Married & 185 & 43.6 \\
\hline Single & 238 & 56.1 \\
\hline Widow & 1 & 0.2 \\
\hline \multicolumn{3}{|l|}{ Ethnic group } \\
\hline Fulani & 66 & 15.6 \\
\hline Hausa & 355 & 83.7 \\
\hline Others & 3 & 0.7 \\
\hline \multicolumn{3}{|l|}{ Level of education } \\
\hline No formal education & 76 & 17.9 \\
\hline Primary & 115 & 27.1 \\
\hline Secondary & 214 & 50.5 \\
\hline Tertiary & 19 & 4.5 \\
\hline \multicolumn{3}{|l|}{ Occupation } \\
\hline Student & 85 & 20.0 \\
\hline Civil servant & 14 & 3.3 \\
\hline Business entrepreneur & 75 & 17.7 \\
\hline Retired & 8 & 1.9 \\
\hline Unemployed & 223 & 52.6 \\
\hline Artisans & 3 & 0.7 \\
\hline Others & 16 & 3.8 \\
\hline
\end{tabular}

Table 3: Age-specific prevalence of positive dengue IgM among febrile patients in secondary health facilities in Kano Metropolis in 2017

\begin{tabular}{cccc}
\hline $\begin{array}{l}\text { Age } \\
\text { group } \\
\text { (years })\end{array}$ & $\begin{array}{c}\text { Respondents } \\
(\mathrm{n}=424)\end{array}$ & $\begin{array}{c}\text { Positive } \\
\text { IgM } \\
(\mathrm{n}=332)\end{array}$ & Age specific prevalence IgM (\%) \\
\hline$<10$ & 81 & 67 & 82.7 \\
$10-19$ & 97 & 80 & 82.5 \\
$20-29$ & 83 & 69 & 83.1 \\
$30-39$ & 80 & 59 & 73.8 \\
$40-49$ & 62 & 43 & 69.4 \\
$50+$ & 21 & 14 & 66.7 \\
& 424 & 332 & 78.3 \\
\hline
\end{tabular}


Table 4: Risk Factors for dengue fever among febrile patients in Kano Metropolis in November 2017

\begin{tabular}{|c|c|c|c|c|}
\hline \multirow[t]{2}{*}{ Variables } & \multicolumn{2}{|c|}{ Dengue Status } & \multirow[t]{2}{*}{ Odds Ratio (95\% CI) } & \multirow[t]{2}{*}{ P-value } \\
\hline & Positive $\mathrm{n}(\%)$ & Negative n (\%) & & \\
\hline \multicolumn{5}{|l|}{ Age group (years) } \\
\hline$<15$ & $106(82.2)$ & $23(17.8)$ & 1 & \\
\hline $15-24$ & $76(87.4)$ & $11(12.6)$ & $1.5(0.69-3.26)$ & 0.30 \\
\hline $25+$ & $150(72.1)$ & $58(27.9)$ & $0.6(0.33-0.97)$ & 0.04 \\
\hline \multicolumn{5}{|l|}{ Gender } \\
\hline Male & $202(78.6)$ & $55(21.4)$ & $1.1(0.65-1.67)$ & 0.85 \\
\hline Female & $130(77.8)$ & $37(22.2)$ & & \\
\hline \multicolumn{5}{|l|}{ Education } \\
\hline Low & $146(76.8)$ & $44(23.2)$ & 0.9 (0y54-1.37) & 0.53 \\
\hline High & $185(79.4)$ & $48(20.6)$ & & \\
\hline \multicolumn{5}{|l|}{ Occupational Status } \\
\hline Unemployed & $260(77.3)$ & $75(22.4)$ & $0.8(0.45-1.47)$ & 0.50 \\
\hline Employed & $72(80.9)$ & $17(19.1)$ & & \\
\hline \multicolumn{5}{|l|}{ Travelled out of Kano } \\
\hline Yes & $77(77.8)$ & $22(22.2)$ & $1.0(0.56-1.80)$ & 0.99 \\
\hline No & $150(77.3)$ & $43(22.3)$ & & \\
\hline \multicolumn{5}{|l|}{ House window nets } \\
\hline 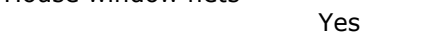 & $286(78.8)$ & $77(21.2)$ & $1.2(0.60-2.21)$ & 0.66 \\
\hline No & $45(76.3)$ & $14(23.7)$ & & \\
\hline \multicolumn{5}{|l|}{ Sleep under nets } \\
\hline Yes & $213(78.3)$ & $59(21.7)$ & $1.0(0.61-1.61)$ & 0.96 \\
\hline$=0$ & $117(78.5)$ & $32(21.5)$ & & \\
\hline \multicolumn{5}{|l|}{ Open gutters/ponds } \\
\hline Yes & $100(73.0)$ & $37(27.0)$ & $0.7(0.40-1.05)$ & 0.08 \\
\hline No & $225(80.7)$ & $54(19.4)$ & & \\
\hline \multicolumn{5}{|l|}{ House near bush } \\
\hline Yes & $86(71.7)$ & $34(28.3)$ & $0.6(0.36-0.96)$ & 0.03 \\
\hline No & $245(81.1)$ & 57 (18.9) & & \\
\hline \multicolumn{5}{|l|}{ Open water containers } \\
\hline 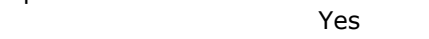 & $103(69.6)$ & $45(30.4)$ & $0.5(0.29-0.74)$ & $<0.01$ \\
\hline No & $228(83.2)$ & $46(16.8)$ & & \\
\hline \multicolumn{5}{|l|}{ Spray environment daily } \\
\hline Yes & $298(79.5)$ & $77(20.5)$ & $1.6(0.79-3.14)$ & 0.20 \\
\hline No & $32(71.1)$ & $14(28.9)$ & & \\
\hline \multicolumn{5}{|l|}{ House near a construction site } \\
\hline Yes & 195 (77.7) & $56(22.3)$ & $0.9(0.53-1.4)$ & 0.54 \\
\hline No & $130(80.3)$ & $32(19.8)$ & & \\
\hline \multicolumn{5}{|l|}{ Waste around the house } \\
\hline Yes & $135(75.0)$ & $45(25.0)$ & $0.7(0.43-1.12)$ & 0.13 \\
\hline No & $185(81.1)$ & $43(18.7)$ & & \\
\hline \multicolumn{5}{|l|}{ Clean Your surroundings } \\
\hline Not regularly & $1(33.3)$ & $2(66.7)$ & $0.1(0.01-1.44)$ & 0.11 \\
\hline Regularly & $310(79.5)$ & $80(20.5)$ & & \\
\hline \multicolumn{5}{|l|}{ Dispose your waste } \\
\hline Not regularly & $24(77.4)$ & $7(22.6)$ & $0.9(0.39-2.24)$ & 0.87 \\
\hline Regularly & $302(78.7)$ & $82(21.4)$ & & \\
\hline \multicolumn{5}{|l|}{ Clean gutters around the house } \\
\hline Not regularly & $43(72.9)$ & $16(27.1)$ & $0.7(0.37-1.31)$ & 0.26 \\
\hline Regularly & $280(79.4)$ & $74(20.6)$ & & \\
\hline
\end{tabular}

\section{Discussion:}

This study found an overall DF IgM positive prevalence of $78.3 \%$ among febrile patients. Having IgM in the blood is an indication of recent infection by the dengue virus or less likely cross-reaction from another flavivirus. The prevalence in this study is high. Possible explanations include the fact that this study was done among febrile patients with suggestive symptoms. Hitherto, such patients were treated presumptively as malaria or typhoid, with or without laboratory confirmation. It is possible that dengue has been the cause of fevers that are treated as malaria but go undetected. In this study, the health providers' preliminary diagnosis was malaria
(46.5\%), typhoid $(20.8 \%)$ or not provided at all. None of the participants had dengue as a presumptive diagnosis, which means though DF does not have any specific treatment, patients may not receive any supportive management in line with DF, with increased risk of possible severe disease and complications.

The GOPD of most public secondary health facilities in Kano are patronized predominantly by people in the lower socioeconomic class. Most middle-and-high income earners prefer private and tertiary care health facilities where they can pay to get better services. Zellweger et al., (15) had suggested that dengue is commoner among people of the lower socioeconomic class. This in part could explain the high DF prevalence in this study. 
Table 5: Independent risk factors for dengue fever among febrile patients in Kano Metropolis, November, 2017

\begin{tabular}{|c|c|c|c|c|}
\hline \multicolumn{2}{|l|}{ Risk factors } & Adjusted odds ratio & \multicolumn{2}{|c|}{ 95\% Confidence interval } \\
\hline \multicolumn{5}{|c|}{ Age group (years) } \\
\hline & $<15$ & 1 & & \\
\hline & $15-24$ & 1.9 & 0.75 & 4.94 \\
\hline & $\geq 25$ & 1.0 & 0.50 & 2.15 \\
\hline \multicolumn{5}{|c|}{ House near bush } \\
\hline & Yes & 0.6 & 0.15 & 2.61 \\
\hline & No & 1 & & \\
\hline \multicolumn{5}{|c|}{ Open gutters/ponds } \\
\hline & Yes & 1.1 & 0.34 & 3.81 \\
\hline & No & 1 & & \\
\hline \multicolumn{5}{|c|}{ Open water containers } \\
\hline & Yes & 0.6 & 0.21 & 1.56 \\
\hline & No & 1 & & \\
\hline \multicolumn{5}{|c|}{ Waste around house } \\
\hline & Yes & 0.9 & 0.50 & 1.75 \\
\hline & No & 1 & & \\
\hline \multicolumn{5}{|c|}{ Spray surrounding daily } \\
\hline & Yes & 1 & & \\
\hline & No & 2.1 & 0.86 & 5.23 \\
\hline \multicolumn{5}{|c|}{ Clean surroundings regularly } \\
\hline & Yes & 1 & & \\
\hline & No & 0.2 & 0.02 & 3.31 \\
\hline
\end{tabular}

Another possible explanation is the fact that this study was carried out in an urban setting. Kano metropolis has seen unplanned urbanization which has been severally identified as one of the risk factors for the increased incidence of DF. When this is associated with low literacy, unemployment and living in densely populated areas where open sewers/ gutters, random waste disposal $(12,13)$ are the norm, which are all present in the study areas, it is not surprising that we obtained such high prevalence of DF. The implication of this finding is that DF is highly prevalent in Kano metropolis, and should be considered as a prominent cause of febrile illness.

The prevalence from this study is higher than some other studies done in other parts of Nigeria. Bello et al., (16) working in Kaduna, located in the same region as our study reported an IgM prevalence of $51.9 \%$, although this was lower, one of the three LGAs (Kafanchan) in which the work was carried out had a prevalence of $80.0 \%$ (indicating disparity even within the same state), which is similar to the results of the current study. On the other hand, Baba et al., (17) working in the arid north-eastern city of Maiduguri repor- ted IgM seropositivity of $0.5 \%$ which may be due to the extreme hot temperature and low rainfall, denying the mosquitoes the necessary breeding grounds. But another study conducted in the same city among internally displaced people (IDP) camps by Oyinloye et al., (10) reported $74 \%$ among antenatal attendees and non-pregnant women and men with febrile complaints. Still in Maiduguri, Idris et al., (18) confirmed that dengue type-3 virus was circulating in the community after obtaining a seropositivity of $10.1 \%$, however this was limited to only one serotype, and the detection method used was culture-based micro-neutralization assay and not IgM ELISA. Adedayo et al., (8) working in Ilorin, northcentral Nigeria, reported a prevalence of $30.8 \%$, however, the study was limited to children under five of age.

Other studies from outside northern Nigeria have reported similar seroprevalence rates. In south-western Nigeria, Oyero et al., (14) working in Ibadan reported a prevalence of $35 \%$ using ELISA that detects the NS1 antigen. However, this antigen is mainly positive during the first 3-5 days of fever and wanes subsequently, thus this could under- 
estimate the prevalence especially where late presentation is the norm. Olufisayo et al., (7) on the other hand, in their study in Ife, reported $25.7 \%$ among febrile patients. Still another study in Ogbomosho by Oladipo et al., (19) reported IgM prevalence of $17.2 \%$, but this was conducted among apparently healthy individuals, thus may not be comparable to the current study.

The rates reported in the studies show the disparity that exists between different studies in the prevalence of dengue fever. Some of these could be as a result of differences in detection methods, population sampled, or regional variation. Bhatt et al., (1) in their work surmised that there could be variation as a result of disparity between actual and reported infection numbers because low proportion of patients with apparent infections seek care from formal health facilities. Elsewhere, beyond Nigeria, MazabaLiwewe et al., (20) working in Zambia, reported $4.1 \%$ IgG seroprevalence rate, while in Sudan, Himatt and colleagues (21) reported a seroprevalence rate of $9.4 \%$ but this was also among apparently healthy individuals in a community-based survey.

The prevalence of dengue-malaria coinfection obtained from this study was $15.8 \%$. This finding indicates that co-infection is common, which is not surprising as both infections are endemic in the environment. This study was conducted in the month of November just after the rainfalls season, when there were still pockets of ground water collections, and when temperature is high, giving conducive environment for mosquito breeding. Thus, this allows for the possibility of the two infections coexisting. That this has not been previously reported in Kano may be due to the fact that there may be no desire to look out for the existence of other febrile illnesses, when one disease can be diagnosed in an acute febrile illness. The implication of this is that health workers should no longer be satisfied with having made a diagnosis but should look further in case there are other coexisting conditions, especially where the mode of transmission is the same or similar. It also stresses the need for early diagnosis and management in all cases of acute febrile illnesses.

Oyero et al., (14) reported a denguemalaria co-infection of $10 \%$ in Ibadan, southwestern Nigeria, which is not too different from what was obtained from the current study. They also concluded that all malaria patients had positive IgG for dengue, indicating previous infection. Similarly, Olufisayo et al., (7) in Ife reported that out of $25.7 \%$ of dengue IgM-positive febrile patients, only 9 $(19.6 \%)$ had no detectable malaria. Also, Barua et al., (22) in Mumbai, India reported a coinfection of $10.25 \%$ and $6.7 \%$ in 2014 and 2015 respectively. However, the co-infection in our study is higher than $3 \%$ reported by Rao et al., (23) in Odisha, India.

The only significant factor in this study associated with the risk of developing DF was age group 25 years and above, who were less likely to develop with DF compared to age group less than 14 years. However, this was not an independent predictor of DF. This finding is not too different from that of Toan et al., (24) in a case-control study during an outbreak who reported that morbidity was highest between the ages 15 and 30 years, and drops as age increased. Other factors that appeared significant include having a house near the bush or harbouring open water containers around the house. But these appeared as protective factors rather than risk factors and eventually were not independently related to dengue infection. The absence of any independent risk factor in this study could be due to the fact that most of the participants had similar background of low socioeconomic setting. This is evidenced by majority having low educational status or being unemployed.

The major limitation of this study is the fact that the population is skewed towards the lower socioeconomic class, being the population that mostly patronize the GOPDs of secondary health facilities. Furthermore, the study was conducted in an urban setting.

\section{Conclusion:}

We found that high proportion of febrile illnesses seen in Kano metropolis were due to DF. Significant proportion of these coexist with malaria. None of these cases were suspected by the health providers and were presumed to be malaria, typhoid, or both or simply as fever of unknown cause. These findings have already been shared with the state ministry of health for action. We recommend that dengue RDT Kits should be made available as a screening test for febrile illnesses. There is need to train health providers to suspect and recognize DF in order to institute the right management of febrile illnesses.

\section{Acknowledgments:}

The authors acknowledge the valuable help provided by staff of the Tuberculosis Reference and Molecular Laboratory, Aminu Kano Teaching Hospital, Kano, especially Muhammad Bashir Kyarama and Abubakar Tukur Dawakin Kudu. The supports of the Kano State Ministry of Health, through the provision of Malaria RDT kits for the study and the staff of the Paediatric side laboratory of the Murtala Muhammad Specialist Hospital, 
Kano are gratefully acknowledged.

\section{References:}

1.

2

4. Amarasinghe, A., Kuritsky, J. N., William Letson, G., and Margolis, H. S. Dengue virus infection in Africa. Emerg Infect Dis. 2011; 17 (8):13491354.

5. World Health Organization (WHO). Dengue vaccine: WHO position paper - July 2016. Wkly Epidemiol Rec Relev épidémiologique Hebd. 2016; 91: 349-364.

6. Ayukekbong, J. A., Mini-Review Dengue Virus in Nigeria: Current Status and Future Perspective. Br J Virol. 2014; 1 (3): 17-27.

7. Olufisayo, A., and Johnson, A. Incidence of Dengue Virus infections in febrile episodes in IleIfe, Nigeria. J Infect Dis. 2016; 10 (1): 21-24.

8. Adedayo, F., Nioma, I., Olanrewaju, M. B., Adeyinka, A., and Ebele, A. Serological Evidence of Recent Dengue Virus Infection Among Febrile Children in a Semi Arid Zone. Am J Infect Dis. 2013; 910 (171): 7-10.

9. Idoko, M., Ado, S., and Umoh, V. Prevalence of Dengue Virus and Malaria in Patients with Febrile Complaints in Kaduna Metropolis, Nigeria. $\mathrm{Br}$ Microbiol Res J. 2015; 8 (1): 343-347.

10. Oyinloye, S. O., Wajiroko, M., Lawan, A. M., et al. Dengue virus infection in northeast Nigeria: Case study of squatters. Int J Perceptions Public HIth. 2016; 1 (1): 59-65

11. NCDC. First Annual Report of the Nigeria Centre for Disease Control. 2017.

12. Mukhtar, M. D., Indabawa, I. I. and Imam, T. S. Public health implications of sewage ponds in Kano metropolis, Nigeria. J Food Agric Environ. 2005; 88 (22): 25-31.

13. Butu, A. W., and Mshelia, S. S. Municipal Solid Waste Disposal and Environmental Issues in Kano Metropolis, Nigeria. Br J Environ Sci. 2014; 2 (2): 10-26.

14. Oyero, O. G., and Ayukekbong, J. A. High dengue NS1 antigenemia in febrile patients in Ibadan, Nigeria. Virus Res. 2014; 191 (1): 59-61.

15. Zellweger, R. M., Cano, J., Mangeas, M., et al. Socioeconomic and environmental determinants of dengue transmission in an urban setting: An ecological study in Nouméa, New Caledonia. PLoS Negl Trop Dis. 2017; 11 (4): e0005471.

16. Bello, O. A., Aminu, M., and Jatau, E. D. Seroprevalence of IgM Antibodies to Dengue Fever Virus among Patients Presenting with Symptoms of Fever in Some Hospitals in Kaduna State, Nigeria. Int J Sci Res. 2013; 14611 (3): 2319-7064.

17. Baba, M. M., and Talle, M. The Effect of Climate on Dengue Virus Infections in Nigeria. New York Sci J. 2011; 44 (11): 28-33.

18. Idris, A. N., Baba, M. M., Thairu, Y., and Bamidele O. Sero-prevalence of dengue type-3 Virus among patients with febrile illnesses attending a tertiary hospital in Maiduguri, Nigeria. Int J Med.
2013; 5: 560-563.

19. Oladipo, E. K., Amanetu, C., Gbadero, T. A., and Oloke, J. K. Detectable anti-dengue virus IgM antibodies among healthy individuals in Ogbomoso, Oyo state, Nigeria. Am J Infect Dis. 2014; 10 (2): 64-67.

20. Mazaba-Liwewe, M. L., Siziya, S., Monze, M., et al. First sero-prevalence of dengue fever specific immunoglobulin $\mathrm{G}$ antibodies in Western and North-Western provinces of Zambia: a population based cross sectional study. Virol J. 2014; 11 (1): 135.

21. Himatt, S., Osman, K. E., Okoued, S. I., et al. Sero-prevalence of dengue infections in the Kassala state in the eastern part of the Sudan in 2011. J Infect Public Health. 2015;

22. Barua, A., and Yeolekar, M. E. Concurrent dengue and malaria coinfection: Observations from a central Mumbai hospital. Int J Infect Dis. 2016; 45: 165.

23. Rao, M. R. K., Padhy, R. N., and Das, M. K. Prevalence of dengue viral and malaria parasitic co-infections in an epidemic district, Angul of Odisha, India: An eco-epidemiological and crosssectional study for the prospective aspects of public health. J Infect Public Health. 2016; 9 (4): 421-428.

24. Toan, D. T. T., Hoat, L. N., Hu, W., Wright, P., and Martens P. Risk factors associated with an outbreak of Dengue fever/Dengue haemorrhagic fever in Hanoi, Vietnam. Epidemiol Infect. 2015; 143 (8): 1594-1598. 